Article

\title{
Short Food Supply Chains and Small Farms-Evidence from Slovakia
}

\author{
Norbert Floriš ${ }^{1, *}$, Pavol Schwarcz ${ }^{1}$, Loreta Schwarczová ${ }^{1}$ and Michal Munk ${ }^{2,3}$ (i) \\ 1 Faculty of European Studies and Regional Development, Slovak University of Agriculture in Nitra, Trieda \\ Andreja Hlinku 2, 94976 Nitra, Slovakia; pavol.schwarcz@uniag.sk (P.S.); loreta.schwarczova@uniag.sk (L.S.) \\ 2 Department of Informatics, Faculty of Natural Sciences, Constantine the Philosopher University in Nitra, \\ Trieda Andreja Hlinku 1, 94901 Nitra, Slovakia; mmunk@ukf.sk \\ 3 Science and Research Centre, Faculty of Economics and Administration, University of Pardubice, \\ Studentska 84, 53210 Pardubice, Czech Republic \\ * Correspondence: norbert.floris@uniag.sk
}

Citation: Floriš, N.; Schwarcz, P.; Schwarczová, L.; Munk, M. Short Food Supply Chains and Small Farms-Evidence from Slovakia. Sustainability 2022, 14, 2728. https://doi.org/10.3390/su14052728

Academic Editor: Riccardo Testa

Received: 10 December 2021

Accepted: 20 February 2022

Published: 25 February 2022

Publisher's Note: MDPI stays neutral with regard to jurisdictional claims in published maps and institutional affiliations.

Copyright: (C) 2022 by the authors. Licensee MDPI, Basel, Switzerland This article is an open access article distributed under the terms and conditions of the Creative Commons Attribution (CC BY) license (https:// creativecommons.org/licenses/by/ $4.0 /)$.

\begin{abstract}
Short food supply chains (SFSCs) is a concept that is relatively new in the conditions of the Slovak Republic, but is developing significantly, mainly with the support of EU policies (CAP, RDP). This paper is focused on the evaluation of the performance of the micro and small agricultural enterprises in short supply chains in the Slovak Republic. We focus on the evaluation of selected economic indicators of small agricultural enterprises and micro-enterprises depending on their participation and non-participation, respectively, in SFSC. Next, we demonstrate the linear relationship between the researched primary and secondary data of enterprises operating inside and outside of the SFSC. Analysing the selected data, we state the ability of farmers operating in the SFSC to produce added-value products and improve their social situation. Additionally, the advantages and disadvantages of associating farmers with SFSCs are demonstrated.
\end{abstract}

Keywords: short food supply chain (SFSC); Rural Development Policy; farmer; Rural Development Programme (RDP)

\section{Introduction}

Short supply chains represent a relatively young concept in the Slovak Republic, using mainly local human and material resources, which is an essential feature of local economic development, based on the endogenous development concept and the internal resources of the locality. In connection with the endogenous development model, it is necessary to emphasize the role that agriculture, as a sector using mainly local material resources, plays in the development of local economies. Agriculture is one of the major sectors of the national economy, as well as one of the most important sectors, providing employment opportunities, especially in rural areas of Slovakia. Demand for food is one of the results of economic development, where "land and water are essential resources for the production of food and thus constitute two of the most fundamental resources for mankind. These resources are under pressure by population growth, economic development, and environmental change" [1]. Increased agricultural productivity can lead to increased economic growth [2]; however, as Marsden and Smith (2005) state [3], "sustainable wealth creation and local economic development within the wider context of sustainable development require new entrepreneurial initiatives that focus on investing in the local environment, creating/strengthening local institutions, and employing people and their resources". They identify three potential dimensions of the value-capture at the producer end of food supply chains. First, more economic value of local producers' products; second, new innovations in the mechanisms for distributing value among producers and processors at the local level (e.g., new types of entrepreneurial activities); and third, these two types of value-capture 
can lead to new potentialities with regard to forging synergies between agricultural practices and different types of multi-functional activities; such as agri-tourism, engagement in off-farm income activities, and environmental schemes and projects [3]. By these statements, the authors respond to the current problems persisting in agriculture, which, as stated by, e.g., Ilbery et al. (2004), "remains as the economic backbone of lagging rural regions with long-established endemic problems, which include geographical remoteness, poor infrastructures, low population densities, limited employment opportunities and poor development capacities" [4]; however, according to De Fazio (2016), the "implementation of farming methods, which are getting more and more intensive, put pressure on the environment, on the sustainability of the agricultural industrial production process and increase the number of kilometres the goods have to travel in order to be distributed" [5]. As De Fazio (2016) further notes, "the lengthening of the supply chain developed over the last decades-due to the multiplication of intermediaries-has produced effects from an environmental, economic, social and territorial point of view cannot pass unnoticed" [5]. The shortening of the supply chain with its important effects such as "economic gains provided by less transportation" [6], but also "the emergence of synergies between agriculture and other rural activities, like tourism and handicraft" [7], seems to be a logical solution to the situation. According to Kneafsey et al. (2013), "shortening the number of links in the supply chain results in increased local sales, increased demand for local services, and increased labour markets" [8]. On the other hand, the distance is important regarding the social and ethical dimensions, where the long-distance trade often implies a loss of information on the product, resulting in the power concentration along the chain [9]. Further study of short supply chains reveals that in this concept the term "local" is endowed with a particular set of values, such as principles of endogenous development, ethical trade, fair treatment of workers, social inclusion, and environmental sustainability [8].

The development of food supply chains in recent years has brought a wide scale of terms and definitions within European and global context as well. Considering the European context, Kneafsey et al. (2013) recognise the two types of food supply chainslocal food systems (LFSs) and short food supply chains (SFSCs) [8]. However, when studying theories on food supply chains, another term occurs, the so-called "alternative food networks" (AFNs), which seems to be an umbrella term covering all the other types of food supply chains. To clarify this status, it is first necessary to explain what the term "alternative food networks" means.

There are several definitions for AFNs. For example, the "creation, operation, and evolution of 'new' or 'alternative' food supply chains is one of the key dimensions of new rural development patterns now emerging" [10]. AFNs are "new and rapidly mainstreaming spaces in the food economy defined by —among other things—-the explosion of organic, Fair Trade, and local, quality, and premium specialty foods" [11]. As Goodman and Goodman (2009) further state, "in the European Union (EU), meso- and macro-level developments are creating new opportunities for AFNs and quality food products as the gradual reform of the Common Agricultural Policy (CAP) is slowly attenuating the pronounced sectoral emphasis on agricultural production and commodity support mechanisms ... this narrow and sectoral productivist focus is giving way to a pluralistic, regionally based and more-endogenous concept of integrated rural development" [11]. Initially, AFN products were sold through charity shops, food co-ops, farm markets, box schemes, and community supported agriculture (CSA) schemes [12], which opened new opportunities to local urban agriculture that is severely threatened by global competition and urban sprawl [13]. At present, however, there is no problem accessing AFN products in supermarkets, both in Western Europe and Slovakia: for example, Maye and Kirwan (2010) report that "around 75 percent of organic produce is sold through supermarkets". This raises the question why supermarkets have such an enormous interest in AFN products, and Maye and Kirwan (2010) offer a very simple answer-because "they have recognized-in response to growing consumer demand, especially from more affluent consumer groups-the huge sales potential of some AFN products" [12]. This also confirms a recent trend of focusing on local 
production, as consumers have become more concerned with quality and traceability [14]. From the point of view of sale forms (charity shops, food cooperatives, farm markets, box schemes or community-supported agriculture), it can be stated that both AFNs and LFSs overlap each other. For example, Kneafsey et al. (2013) classify the last three schemes within the local food systems (LFSs) - the food supply chains limited by the geographic area and involving the whole life cycle of the food, i.e., from its production to its sale [8]. From the neighbouring countries, we have more detailed information on the implementation of AFNs from the Czech Republic. After November 1989, AFNs are mainly associated with farm markets and farm shops providing the high-quality local food produced by traditional methods. In Slovakia, AFN implementation is especially associated with farm direct sales [15], which, as follows from the Manifesto of the Government of the SR, were to ensure the sale of small quantities of animal products and thus create better conditions for rural development. Support for the farm direct sales was within the Rural Development Programme SR 2007-2013 under Axis 1: Improving the competitiveness of the agricultural and forestry sector, priority Support of modernization, innovation and effectiveness of the agricultural and forestry sector, measure 1.1: Modernisation of agricultural holdings [16]. The support was for the construction, reconstruction, and modernization of farm buildings for the direct sale of agricultural products through small retail outlets located in the businesses themselves, where the recipients of aid can sell their own products. The applicant could submit one project for plant production, one for animal production, and one for farm direct sales.

Although often associated with other concepts such as "local food", "alternative food chains", "local food systems", or "direct sales" [17], a detailed observation of short food supply chains will show that these represent the scheme with different characteristics and typology.

Van der Ploeg (2000) defines new food supply chains as a "commonly recurring phenomenon in several fields of rural development centred around distinctive product qualities including organic farming, high quality production and region-specific products" [18]. Short food supply chains (SFSCs) are based on their capacity to re-socialize or re-spatialize food, thereby allowing the consumer to make value-judgements about the relative desirability of foods based on their own knowledge, experience, or perceived imagery [19]. The short supply chain has a positive effect on public goods, with overt environmental benefits, when compared to the long supply chain [20]. The SFSC concept is more specific than AFNs, and, rather, covers (the interrelations between) actors who are directly involved in the production, processing, distribution, and consumption of new food products [10]. As the term "short" indicates, there is a significant emphasis put on minimising the distance which the food has to overcome travelling from the producer to the consumer's table. Consumers do not need to travel long distances in order to purchase their desired favourite food from the farmer, food producer, or processor. From the consumers' point of view, this saves both time and travel costs. The factor of minimising the distance indicates the connection of the SFSC concept with direct sales, which, in fact, allows the consumer to buy higher quality, healthy, and seasonal products, promoting the territory with the marketing of local food products, reducing the distances travelled by food to reach the final consumer, and promoting a network of local producers more tied to the territory, which is more sustainable from an environmental perspective [21]. In addition to the distance, the number of intermediaries is often indicated as a discriminating factor to define SFSCs [22]. The economic benefits are equally important from the perspective of the farmer/producer/processor; the long-term survival would probably not be possible without the profit [23]. Some authors (Malak-Rawlikowska et al., 2019) state that participation in SFSC is beneficial for producers, first of all, from an economic perspective [24]. Shortening supply chain distances can have a positive impact on local sales, employment, and multiplier effects, while the short supply chain itself can become an important component of regional tourism. However, as Kneafsey et al. (2013) state, "the relative importance of local sales or SFSCs will vary in relation to enterprise size 
and scale, as well as geographical location (e.g., proximity to urban markets or tourism destinations)" [8]. Concerning the success, farmers "may interpret success not in narrow economic terms, but in terms of their social and environmental contribution and lifestyle factors". Galli and Brunori (2013) offer a similar view of the economic aspects of SFSCs, but stress the importance of SFSCs, especially for SMEs, which "are often less competitive in the conventional chains due to their higher costs of production (because of the lack of economies of scale and the different organisation of production processes) and the higher prices" and which can increase their economic viability thanks to the fair access to the market [17]. However, some authors perceive the revenues of farmers and the economic weight of SFSCs in the local economy to be neutral elements, stating that the SFSCs do not necessarily lead to increased added value on farms [25]. Environmental aspects of SFSCs have been the subject of long-term discussions-logically, shortening the distance in the supply chain should result in a reduction in greenhouse gas emissions. However, according to Kneafsey et al. (2013), "the methods of production and of processing are important for ensuring less environmental impact; 'local' and /or 'short' is not necessarily better, although the importance of ethical values and the higher uptake of environmentally sound practices are de facto elements in favour of a positive impact of SFSC in the EU" [8]. According to Galli and Brunori (2013), "SFSC are not by definition more environmentally friendly than conventional, longer supply chains [17]. To that regard, the impact of production methods, processing, packaging, distribution, cooling, transport and waste in each chain should be considered". However, in some cases, there is a positive contribution of SFSCs to environmental sustainability, e.g., reducing fossil fuels or packaging and reducing the amount of pesticides used or their complete removal.

The most highlighted factor is, however, the "development of trusting relationships between producers and consumers" [8]. Kneafsey et al. (2013) further state how the social impacts of the SFSCs can differ, depending on their type. While the traditional farm-based SFSCs are likely to maintain traditional plant and animal production and thus contribute to the viability of rural communities, the social impact of "neo-traditional" types of SFSCs is more likely to be in the form of community-building, knowledge exchange, skills development, and health and well-being [8]. Collaborative and collective approaches are very important for the traditional and neo-traditional SFSCs; small producers can benefit from working with others-including other producers, consumers, and institutions [8]. Galli and Brunori (2013) provide a similar look on social aspects of the SFSCs, where the "social sustainability of SFSC refers to their capacity to contribute to the equity or fairness among food chain actors, food security and the viability of local communities" [17]. Maye and Kirwan (2010) correlate the economic aspects of alternative networks with the concept of "social embeddedness", where "economic behaviour is embedded in, and mediated by, a complex and extensive web of social relations" [12]. Other authors perceive the SFSCs as a new opportunity for the marketing of farm products, thanks to their possibility of bringing down the cost of food outputs and their ability to create a direct relationship between the producer and consumer [26]. The social aspect based on building a relationship between the farmer/producer/processor and his customers and the personal contact of both actors reinforced by mutual trust is a key characteristic of this relationship. The farmer is aware of his customer's importance for his business and the customer is aware of the quality of the products-local, natural, and healthy - provided by the farmer. If these characteristics are contained in the information and product embedded with this information (for example, printed on the package or communicated in the face-to-face contact) reaches the customer, it allows him to make the association with the place of production [19].

There are three main types of SFSCs identified-face-to-face, spatial proximity, and spatial extended. Marsden et al. (2000) provide their characteristics as follows:

1. Face-to-face-Consumer purchases a product directly from the producer/processor on a face-to-face basis. Authenticity and trust are mediated through personal interaction. The Internet also now presents opportunities for a variant of face-to-face contact through on-line trading and web pages. 
2. Spatial proximity-Products are produced and retailed in the specific region (or place) of production, and consumers are made aware of the local nature of the product at the point of retail.

3. Spatially extended-Where value and meaning laden information about the place of production and those producing the food is translated to consumers who are outside of the region of production itself and who may have no personal experience of that region [19].

The main objective of this paper is to assess the implementation of a short food supply chain in the conditions of the Slovak Republic. The partial objectives are as follows:

1. To assess the performance of farmers in short food supply chains in terms of meeting the objectives set out in the Rural Development Programme of the Slovak Republic 2014-2020 (RDP), in particular achieving a higher added value of the products offered and improving the social situation through increased incomes.

2. To assess the advantages and disadvantages of grouping farmers into short food supply chains, especially in terms of selected economic factors.

\section{Materials and Methods}

As we stated in the theoretical part of the paper, micro, small, and medium-sized enterprises are at a significant disadvantage in the conventional food chain compared to large farms, mainly due to the high production costs and prices at which they sell their products. On the other hand, they are an important source of innovation in the organization of the food chain, with the EU's Common Agricultural Policy aiming to help ensure the livelihoods of millions of small farmers in the European Union while promoting competitive and sustainable agriculture. The focus is on how small farmers are able to meet the growing consumer demand for high quality and traceable food that supports local economies and communities. In connection with the above, when collecting data in order to achieve the objectives set in the paper, we focused primarily on micro and small enterprises, as we assumed that, due to providing products to local customers (local consumers, schools, social services), their products achieve a higher added value due to higher quality. The collected primary and secondary data were processed using a suitable analytical method.

When selecting entities for the purpose of primary data collection, we proceeded in accordance with the quantitative criteria on the basis of which the short food supply chains are defined within the RDP [27], as follows:

- A radius of $100 \mathrm{~km}$ from the place of origin of the product or the territory of a higher territorial unit in which the enterprise of origin of the product is located for the local market within which the farmer provides his products to consumers.

- A maximum of one intermediary between the farmer and the consumer.

The data were collected using the questionnaire method, where all applicants within the RDP sub-measure 16.4 Support for horizontal and vertical cooperation between the supply chain actors in setting up and developing short food supply chains and local markets and for promotional activities in the local context related to the development of short food supply chains and local markets, the School Milk and School Fruit and Vegetables scheme, as well as applicants within the RDP sub-measures 4.1 Support for investment into agricultural enterprises and 4.2 Support for investments for processing/placing on the market and/or developing agricultural products were surveyed. The statistical population included 180 enterprises. The sample included 60 enterprises, while 43 questionnaires were filled in so that they were suitable for processing. The secondary data were obtained from the EUROSTAT database for the periods 2005, 2007, 2010, 2013, and 2016 [28,29], the Agricultural Paying Agency (summary overview of the RDP project measures) for 2017 and 2020 [30,31], and from the Register of Financial Statements of the Ministry of Finance of the Slovak Republic [32]. 
1. To achieve the set objectives, the analysis of the combination of primary and secondary data was used. The factors that directly affect the economic result of an enterprise, namely the operating income and operating expenses, were examined. The data on the above factors were obtained from secondary sources, specifically from the Register of Financial Statements. The economic result of small and medium-sized agricultural enterprises is also influenced by the added value, for which we used the data on the revenue from the sale of own products of individual enterprises. The amount of supports-direct payments-is another important factor influencing the economic result.

Data on higher added value and on the supports were obtained directly through a questionnaire, which in addition to the above data also provides basic information about companies (main activity, method of production, legal form, etc.) as well as information on the operation of companies in short food supply chains, where the enterprises were asked to identify benefits gained through operating in short food supply chains, but also forms of cooperation. Apart from the analysis and comparison of primary and secondary data, it was necessary to estimate the relationship between them, using the following multiple linear regression model.

$$
Y_{i}=\beta_{0}+\beta_{1} x_{i 1}+\beta_{2} x_{i 2}+\beta_{3} x_{i 3}+\beta_{4} x_{i 4}+\beta_{5} x_{i 5}+\varepsilon_{i}, i=1,2, \ldots, 20,
$$

where the dependent variable $Y$ was the operating income and the independent variables $\boldsymbol{X}$ were as follows:

- The independent variable $X_{1}$ is membership in an SFSC/producer group, which we denote as a dichotomous variable by the numerical value 1 in case of membership of the enterprise in an SFSC/producer group or 0 in case the enterprise is not a member of an SFSC/producer group.

- $\quad$ The independent variable $X_{2}$ is the revenue from sale of own products.

- $\quad$ The independent variable $X_{3}$ is the area on which the enterprise operates.

- $\quad$ The independent variable $X_{4}$ is the number of employees.

- $\quad$ The independent variable $X_{5}$ is the amount of direct support and its arithmetic means in individual monitored years.

To create a basic regression model, the forward stepwise method of regression analysis was used [33], adding independent variables individually to the model at each step of the regression until the best regression model was achieved. From the correlation/scatter plots of residuals and independent variables, it was determined whether the residual equal variance assumption was met. If the assumption would not be met, the violation would be removed by transforming the dependent variable and then creating a new regression model. Assumptions of using linear regression analysis-the linear relationship between the dependent variable $Y$ and the independent variables $X$-were verified by means of correlation.

\section{Results}

As we state in the methodological part, the collection of primary data took place through a questionnaire, while all applicants for a non-repayable financial contribution from sub-measure 16.4 under the RDP and under the School Milk and School Fruit and Vegetables programs were interviewed. In order to obtain more data, the questionnaire was also sent to companies that were applicants under sub-measure 4.1. The questionnaire was sent to a total of 180 companies, while the data in the questionnaire were completed by 43 companies. The purpose of the questionnaire was to obtain detailed information on the companies in terms of their main activity, the aid received, as well as on the way the products were sold and the associated short supply chain or producer organization. The questionnaire consisted of three basic parts:

1. Part I-Basic data provide information on the legal form of the enterprises surveyed, the method of production and main activity (cultivated crops, processed products, 
and farmed animals), the total area, the number of employees, and the number of farmed animals in the observed period.

2. Part II-The economic result and support provide information on the economic data of the surveyed enterprises in the observed period, as well as on the amount of direct support and sub-measures of the RDP SR 2007-2013 and RDP SR 2014-2020, within which the companies received a non-repayable financial contribution.

3. Part III-The method of product sale, product quality, environmental and social aspects of operating in the short supply chain, and cooperation provide information on the method of product sale, product Slovak trademark (SK trademark) or regional quality trademarks, as well as data on the operation of companies in the short supply chain or sales organization producers.

As the majority of enterprises (76\%) also sell products directly in the enterprise, we consider enterprises operating in the short supply chain as those ones which are members of Sales Producer Organizations-POs (eight companies) and those which have signed a non-repayable financial contribution agreement with the Agricultural Paying Agency under the sub-measure 16.4 Rural Development Programme of SR 2014-2020 (nine companies). In total, we considered 17 enterprises to be those operating in the short supply chain.

Figures 1 and 2 provide data on the number of enterprises surveyed by size and by the method of production, comparing enterprises operating in SFSCs in POs with companies that do not operate in them, respectively. In the case of size, small and medium-sized enterprises predominate in SFSCs. From the point of view of the method of production, the situation is more balanced; while in the case of enterprises in the SFSC, primary producers predominate slightly, in the case of enterprises outside the SFSC, processors predominate.

Data on the main activity of enterprises are provided in Figure 3, while we used the statistical classification of economic activities in the European Community NACE to define their main activity. The majority of companies in both groups are engaged in the cultivation of stone fruit, in which apple growing and apple production predominate, as well as the processing and canning of other fruits and vegetables, in which the production of fruit and vegetable juices predominates. Other activities are related to vineyard and wine production, cereal growing, livestock breeding, and bakery production. As part of the cultivation of vegetables and melons and root and tuber vegetables, the companies are mainly engaged in the cultivation of peppers and tomatoes. The production of cheese and bryndza (sheep milk cheese) predominates among dairy products.

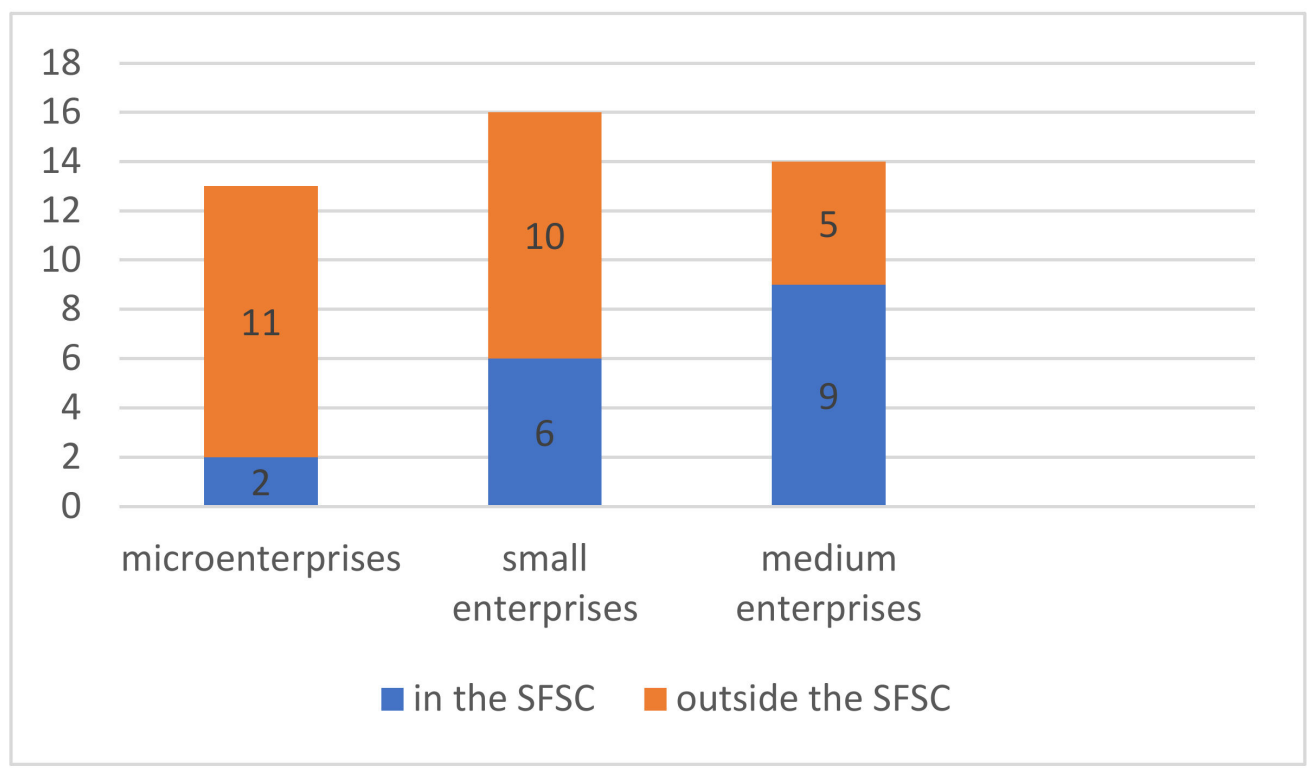

Figure 1. Number of enterprises surveyed by size. Source: Own processing. 


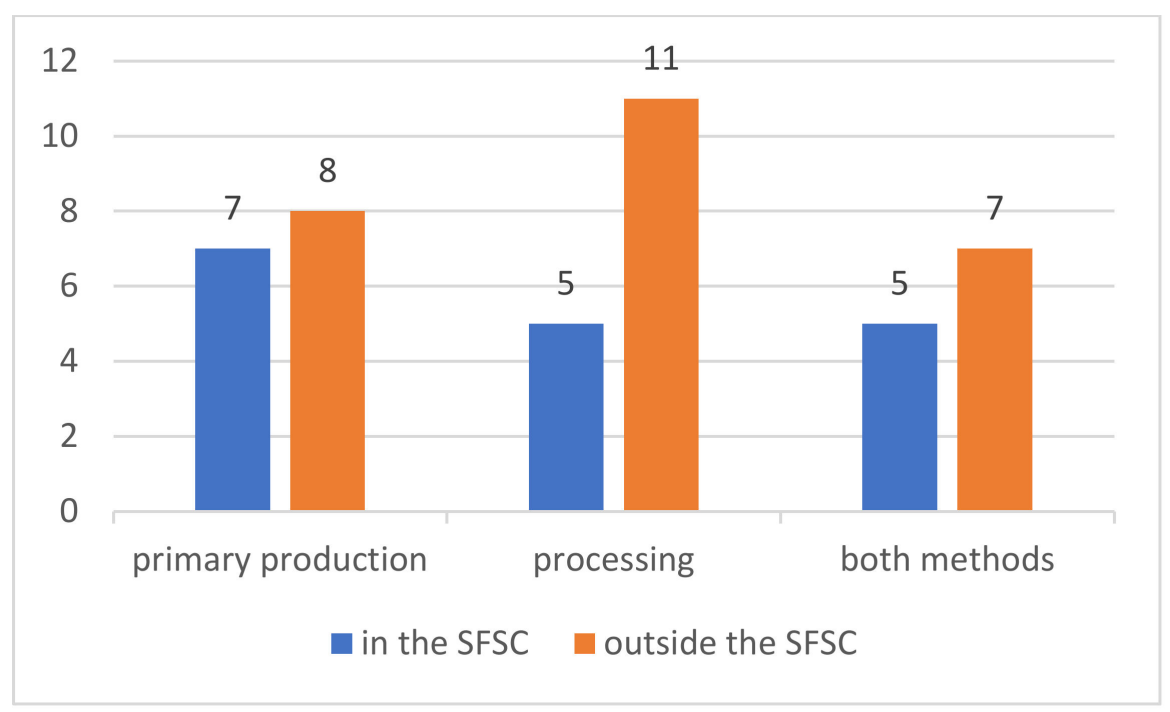

Figure 2. Number of enterprises surveyed by method of production. Source: Own processing.

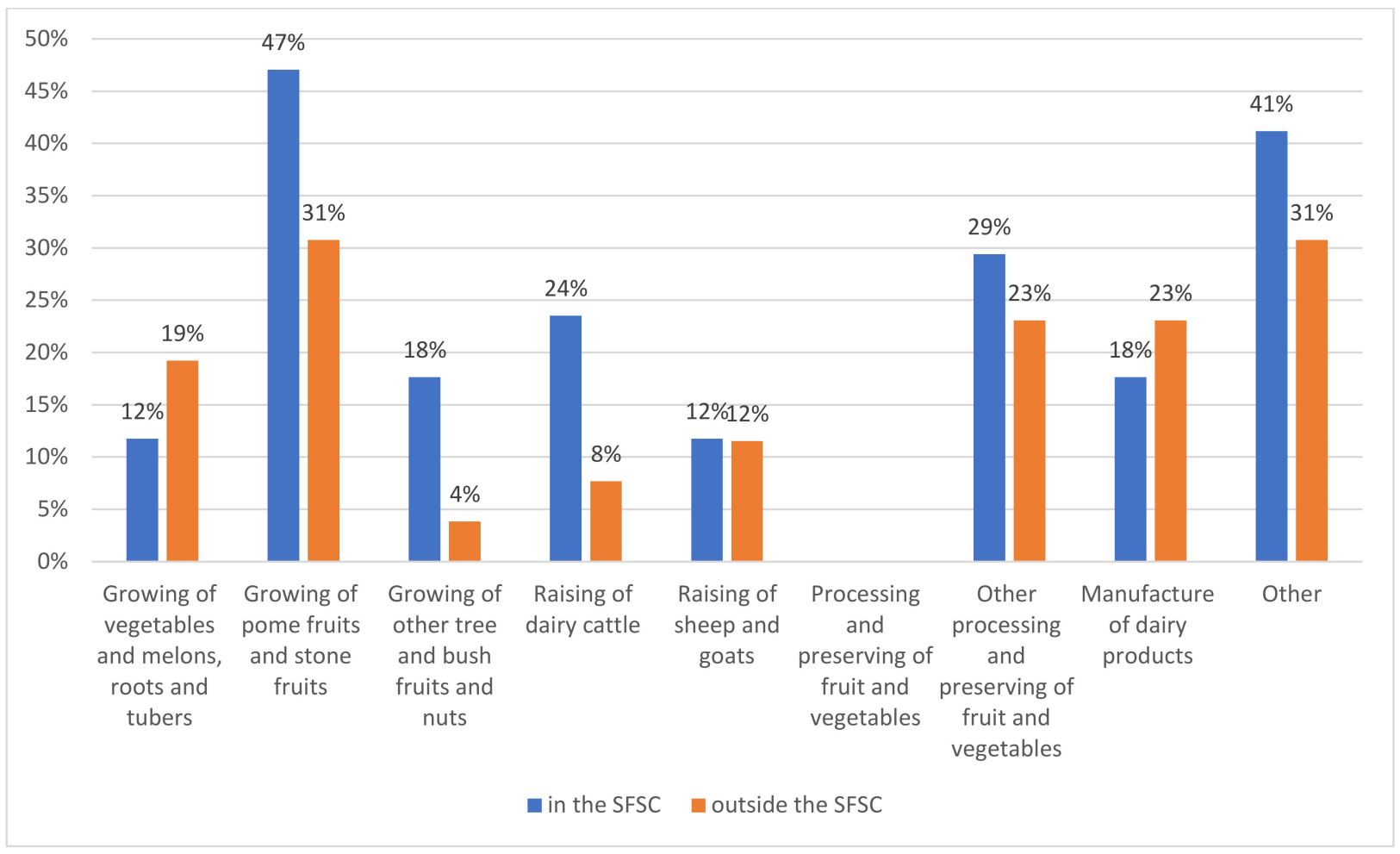

Figure 3. The share of enterprises surveyed by main activity. Source: Own processing.

In accordance with the methodology, we further verified whether farmers operating in short supply chains achieve a higher added value of their products. We used a combination of primary data obtained from the questionnaire and the secondary data. When selecting primary data, we assumed that the added value of products produced by primary producers/processors within short supply chains lies primarily in their increased quality, which is reflected in higher product sales. When assessing the increased quality of products, we processed the following primary data:

- Sales method-Shortening the distance between the place of production and the sale of a product is one of the most important aspects of short supply chains, which is not 
just economic benefits (e.g., reduction of transport costs) or environmental benefits (e.g., reduction of exhaust emissions). In the literature and references available on short supply chains, the term "local" is combined with the term "quality". Quality local products are directly related to one of the goals of the RDP SR 2014-2020, which is to process $80 \%$ of domestic production by 2020 through an increased share of domestic production with a higher added value through the production of higher quality products, the introduction of innovations in production, the offer of regional and local specialties, etc. We assume that the products sold directly in the enterprise, or at the place of their production, reach customers in fresh form and without damage caused by their transport. We primarily focus on companies that apply direct sales of products.

- $\quad$ Aid received from the RDP (sub-measures 1.1, 1.2, 4.1, 4.2, and 16.4) - In the monitored period, enterprises drew aid under sub-measures 1.1 and 1.2 of the RDP SR 2007-2013, while they were provided with aid under investment sub-measures 4.1 and 4.2 and within sub-measure 16.4 RDP SR 2014-2020. Assistance under sub-measure 4.1 mainly concerned investments in technical and technological equipment of animal production and special crop production, the planting of orchards, repairs/reconstruction of workshops and warehouses, the purchase of machinery, and investments in innovative cheese processing plants or the purchase of mini-dairy equipment. The aid under sub-measure 4.2 concerned investments in product processing technologies; investments in direct sales shops; purchases of cottage cheese packaging lines; technological equipment for cheese production; innovations in production technologies; the modernization of production and storage premises; the establishment of a food operation; the purchase of technology, equipment, and internal equipment of the store; the reconstruction of storage equipment; and the establishment of a logistics unit. A substantial part of the aid under the investment measures was related to modernization and the introduction of innovations in production. The assistance under sub-measure 16.4 mainly concerned the creation of short supply chains for cooperation between individual companies. From the products quality enhancement point of view, the assistance received under the above-mentioned sub-measures of the RDP SR 2014-2020, which mainly concerned the modernization of production and the introduction of innovations, is fully in line with the above-mentioned objective of the RDP.

- $\quad$ Advantages of working in short supply chains (SFSCs) and in producer organizations (POs) or enterprises have the opportunity to indicate whether enterprises benefit from operating in the SFSCs and POs (Part III of the questionnaire). Among several more options, enterprises mentioned better products, value-added products, and innovations in production as advantages of operating in the SFSCs and POs.

We focus on enterprises (Figure 4) that apply the established primary data for the whole reference period. Assuming that the increased quality of the products directly affects their sales, we determined the sales of our own products as a secondary figure, calculating their arithmetic mean for each reference year separately for enterprises in SFSCs and separately for non-SFSC enterprises. The course of the arithmetic mean of revenue from the sale of own products for both groups of companies is shown in Figure 5.

The course of the established primary data shows some advantages in favour of companies in the SFSCs. While direct sales are applied equally by both enterprise groups (76\% of SFSC enterprises), up to $65 \%$ of SFSC enterprises apply climate and environmental farming practices and 53\% of SFSC enterprises have benefited from RDP sub-measures. While $35 \%$ of companies in the SFSC consider better products and value-added products as an advantage of operating in the SFSC and innovation in production is considered an advantage by $18 \%$ of companies, $8 \%$ of companies outside the SFSC believe that operating in the SFSC could bring them benefits in the form of better products. 


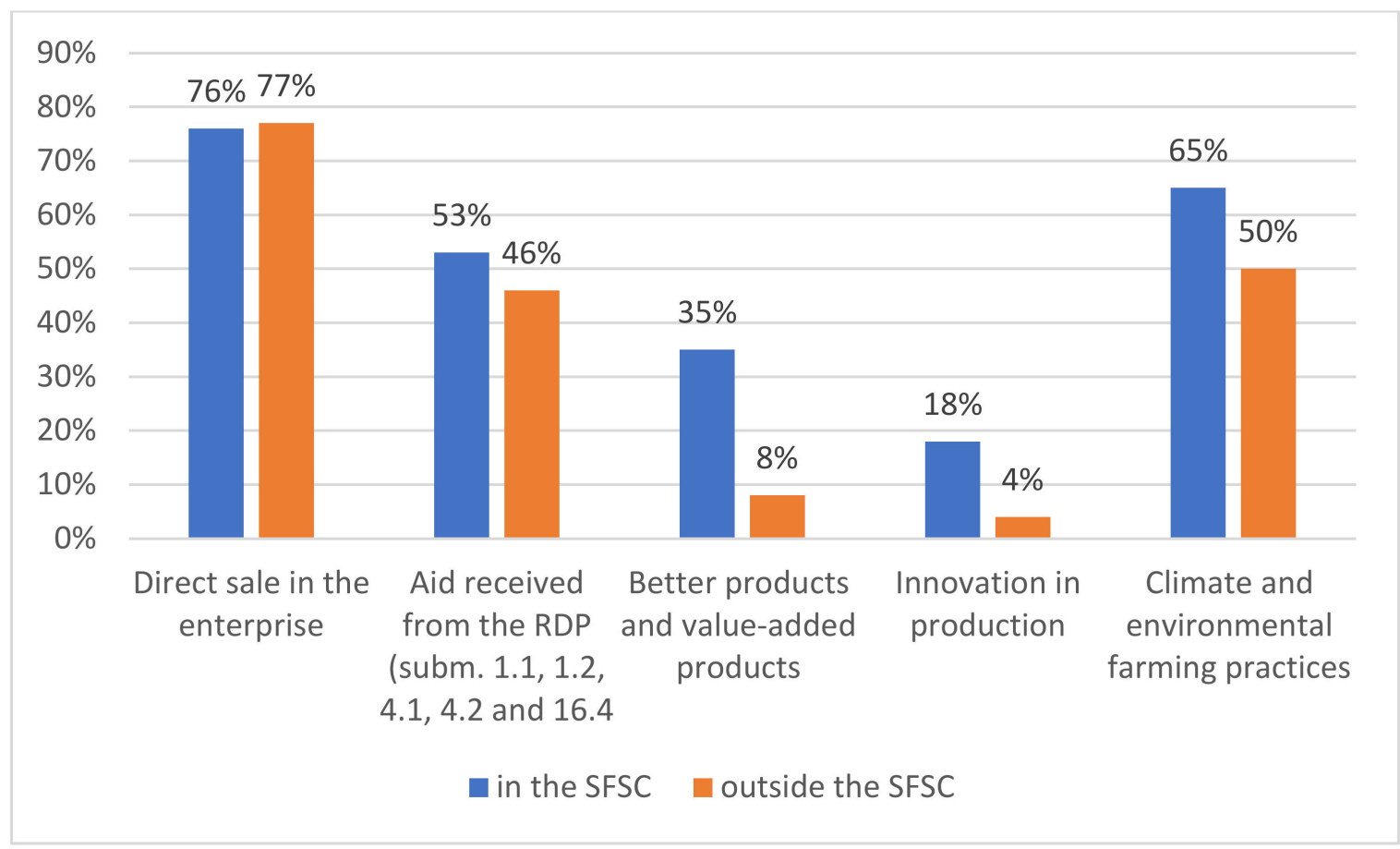

Figure 4. Comparison of enterprises in SFSC and outside them according to selected primary indicators. Source: Own processing.

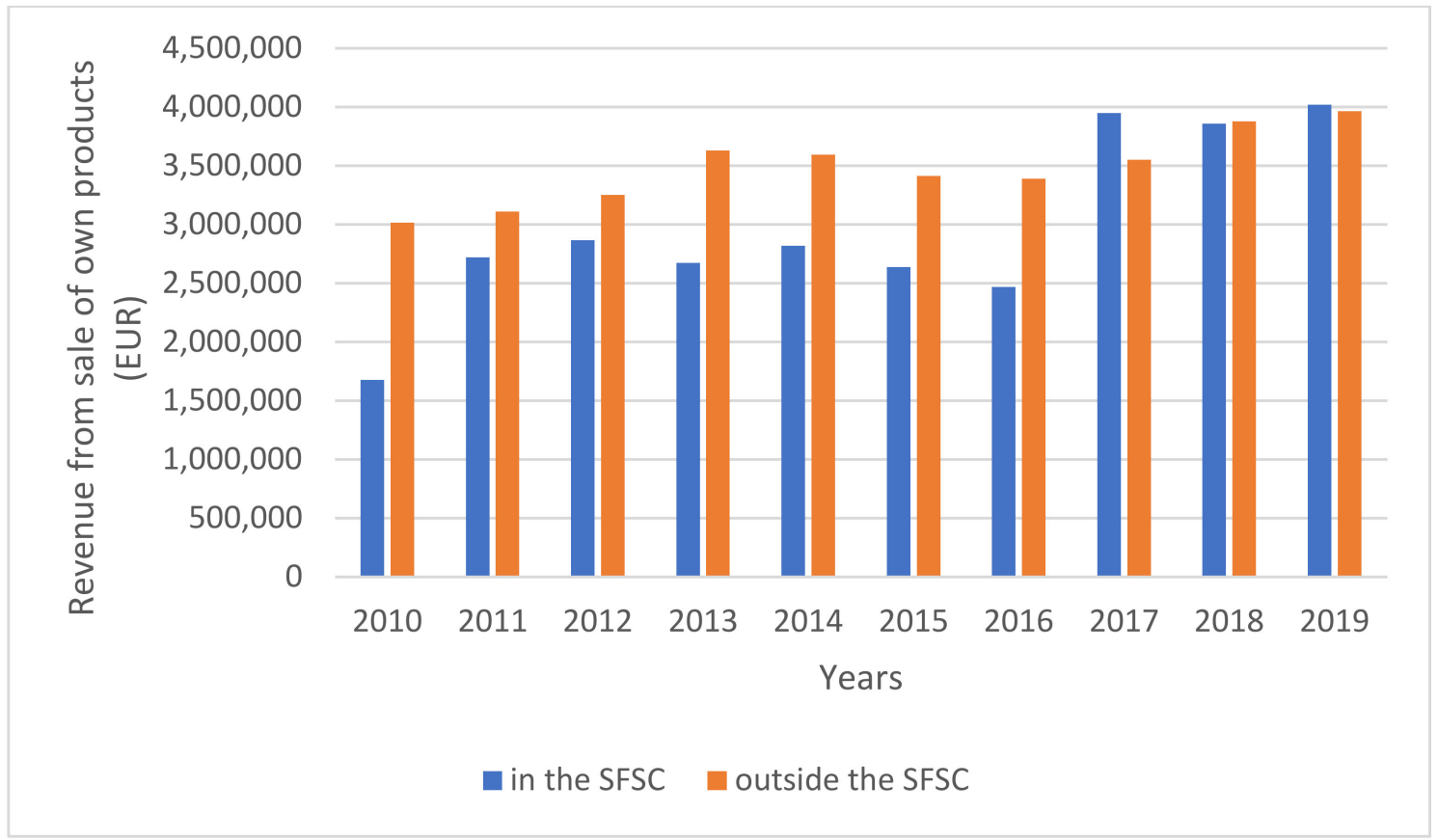

Figure 5. Comparison of enterprises in and outside the SFSC according to the arithmetic mean of revenue from sale of own products (EUR). Source: Own processing.

The course of sales of own products (Figure 5) indicates their increasing trend, especially for enterprises in the SFSC in the last three monitored years, i.e., 2017, 2018, and 2019, when enterprises signed contracts with the Agricultural Paying Agency under sub-measure 16.4. We can consider the year 2017 as the beginning of their operation in the SFSC and we can also assume that the increased quality of their products had a positive effect on the development of their sales of own products. From the analysis of the primary and 
secondary data, we can state that farmers operating in short supply chains achieve a higher added value of their products.

We also monitored the benefits of operating enterprises in the SFSC in POs. Within the secondary data, we monitored the economic result from economic activity, from which we determined the arithmetic mean for each monitored year separately for companies in the SFSC and separately for companies outside the SFSC. As part of the questionnaire, enterprises had the opportunity to answer the following questions about the benefits of working in the SFSC and improving the social situation of their families:

- Does operating in a short supply chain (or POs) bring benefits to your company? If so, how are they reflected?

- Has the social situation of you and your family improved as a result of your business in the short supply chain? If so, how is the improvement reflected?

Enterprises had the opportunity to list several options. The results of the first question are processed in Figure 6 . The vast majority of companies (88\%) stated better marketing as the advantage of their operation in the SFSC, while $76 \%$ of companies cited improved product sales as another benefit and $35 \%$ cited better and value-added products as one of the benefits. All companies within the SFSC stated that their activities in the SFSC improved the social situation of their families through increased incomes.

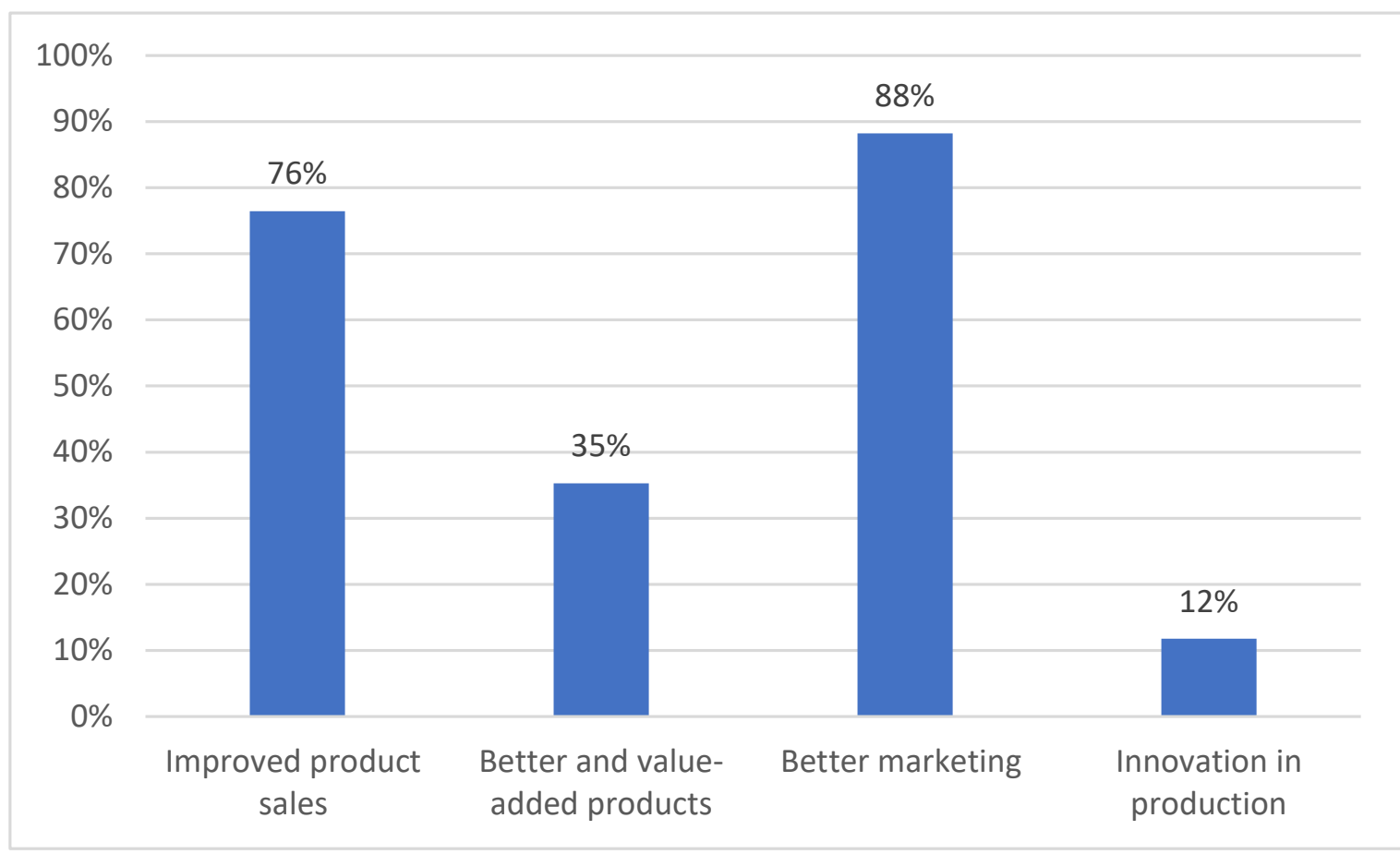

Figure 6. Comparison of enterprises in the SFSC according to selected primary indicators. Source: Own processing.

As we state in the Section 2 (and as many authors in the literature also state), the main disadvantages of micro and small farms compared to large farms are the high production costs and prices at which they sell their products. In particular, the higher prices of products offered by micro and small enterprises are an important factor that puts them at a considerable disadvantage compared to conventional supply chains, for which it is advantageous to have cheaper products from abroad. Up to $67 \%$ of all companies surveyed identify cheaper products from abroad as one of the obstacles to the prosperity of their company and to production itself. The solution is to reduce the distance in the supply chain as much as possible in order to minimize transport costs, as well as measures to improve product sales. 
From the secondary data, we monitored the development of costs for the economic activity of companies in the SFSC and outside the SFSC. For these data, we calculated the arithmetic mean for each reference year.

Figure 7 provides information on how businesses in the SFSC cooperate. As many as $89 \%$ of enterprises prefer cooperation in the form of the joint marketing of products, which indicates that companies prefer their promotion as part of measures to improve the marketing of their products. On the contrary, measures to reduce transport costs are significantly lower. Only $22 \%$ of companies within the SFSC cooperate in logistics and transport. The companies also cooperate in the same way in the area of joint production, the development of joint projects, joint business plans, and in the sharing of storage premises. Only $11 \%$ of companies in the SFSC cooperate in launching new products on the market. The analysis of the forms of cooperation between enterprises in the SFSC thus indicates their focus on improving product sales through joint product marketing. This statement is also supported by the fact that better marketing and improved product sales were marked by $88 \%$ and $76 \%$ of companies, respectively, as the benefits of their operations in the SFSC (Figure 6). In connection with the above statements, as well as in connection with the development of sales of own products in the period under review (Figure 5), we can state that the targeted cooperation of companies in SFSCs brings benefits to farmers.

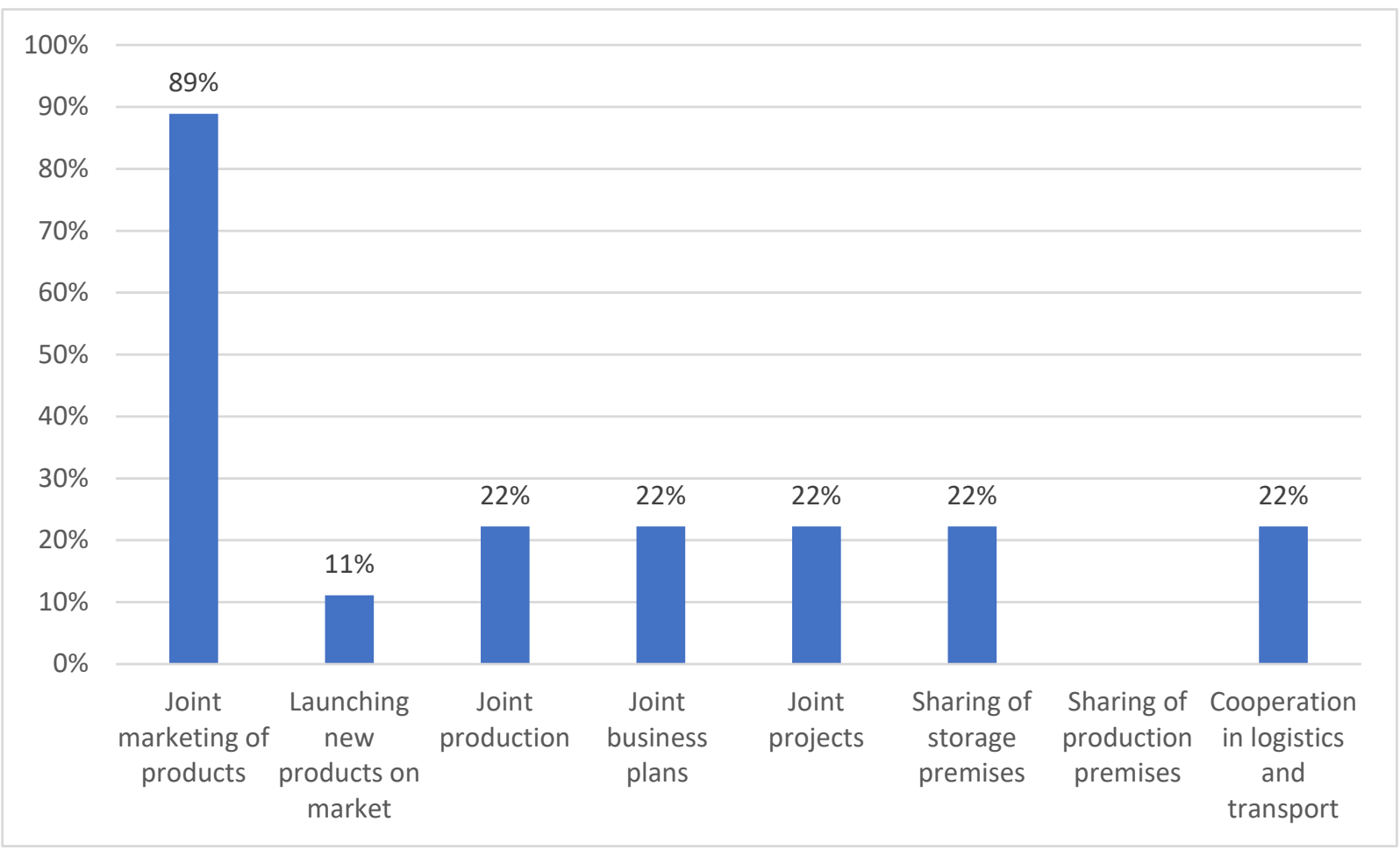

Figure 7. Forms of business cooperation in SFSC. Source: Own processing.

The distances that companies travel to the point of production to the point of sale are shown in Figure 8. 


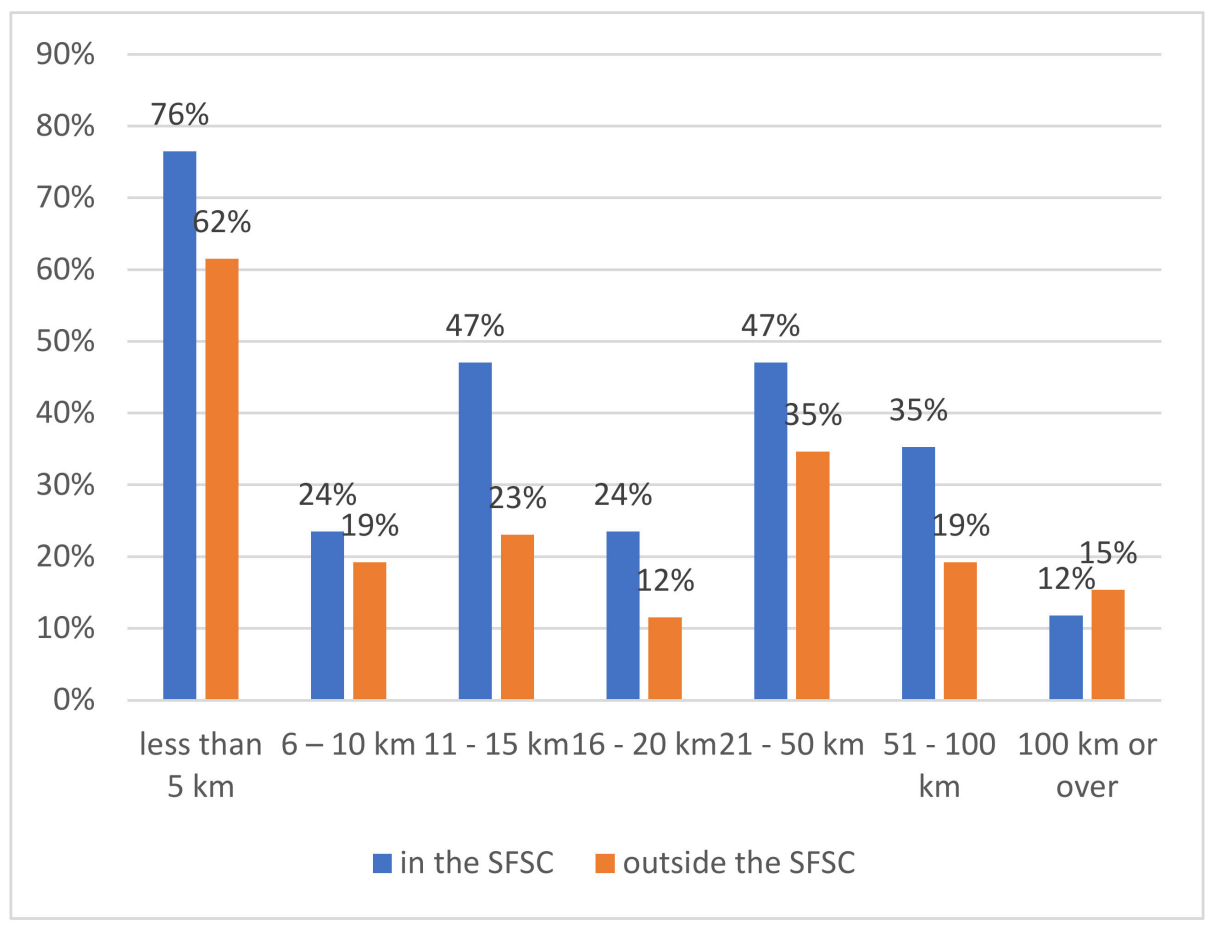

Figure 8. Comparison of SFSC and non-SFSC enterprises by distance between place of production and sale of products $(\mathrm{km})$. Source: Own processing.

As many as $76 \%$ of SFSC enterprises sell their products within $5 \mathrm{~km}$ of the place of production place, $47 \%$ of companies import their products to the point of sale within a distance of 11-15 km and 21-50 km, 35\% of companies in the SFSC import products to the point of sale within a distance of $51-100 \mathrm{~km}$, and $12 \%$ of companies import products over $100 \mathrm{~km}$.

Figure 9 provides information on the opportunities that companies use to sell their products outside the place of their production.

The vast majority of enterprises sell their products directly at their place of production, i.e., in the enterprise ( $76 \%$ of companies in the SFSC and $77 \%$ of companies outside the SFSC). Enterprises that sell their products on the market in the district town are represented almost equally ( $5 \%$ of enterprises in the SFSC and $4 \%$ of enterprises outside the SFSC). A total of $18 \%$ of enterprises in the SFSC and $23 \%$ of enterprises outside the SFSC supply their products to retail chains, such as BILLA, Tesco, or COOP Jednota. A total of $47 \%$ of enterprises in the SFSC (compared to 31\% of enterprises outside the SFSC) use other ways of selling their products off-premises, mainly in their own company stores in other municipalities and cities. Interestingly, the local market does not use any business to sell its products.

In connection with the costs incurred by enterprises in transporting products over different distances in connection with different ways of selling products, we monitored the secondary data-the operating expenses of enterprises in the SFSC and outside the SFSC. Given the large amount of data in the observed 10-year period, we calculated an arithmetic mean for enterprises in the SFSC and beyond for each reference year, comparing both groups of enterprises (Figure 10). Figure 10 shows much higher costs for the economic activity of enterprises in the SFSC, which may also be due to the fact that almost $53 \%$ of the surveyed enterprises operating in the SFSC are medium-sized companies. 


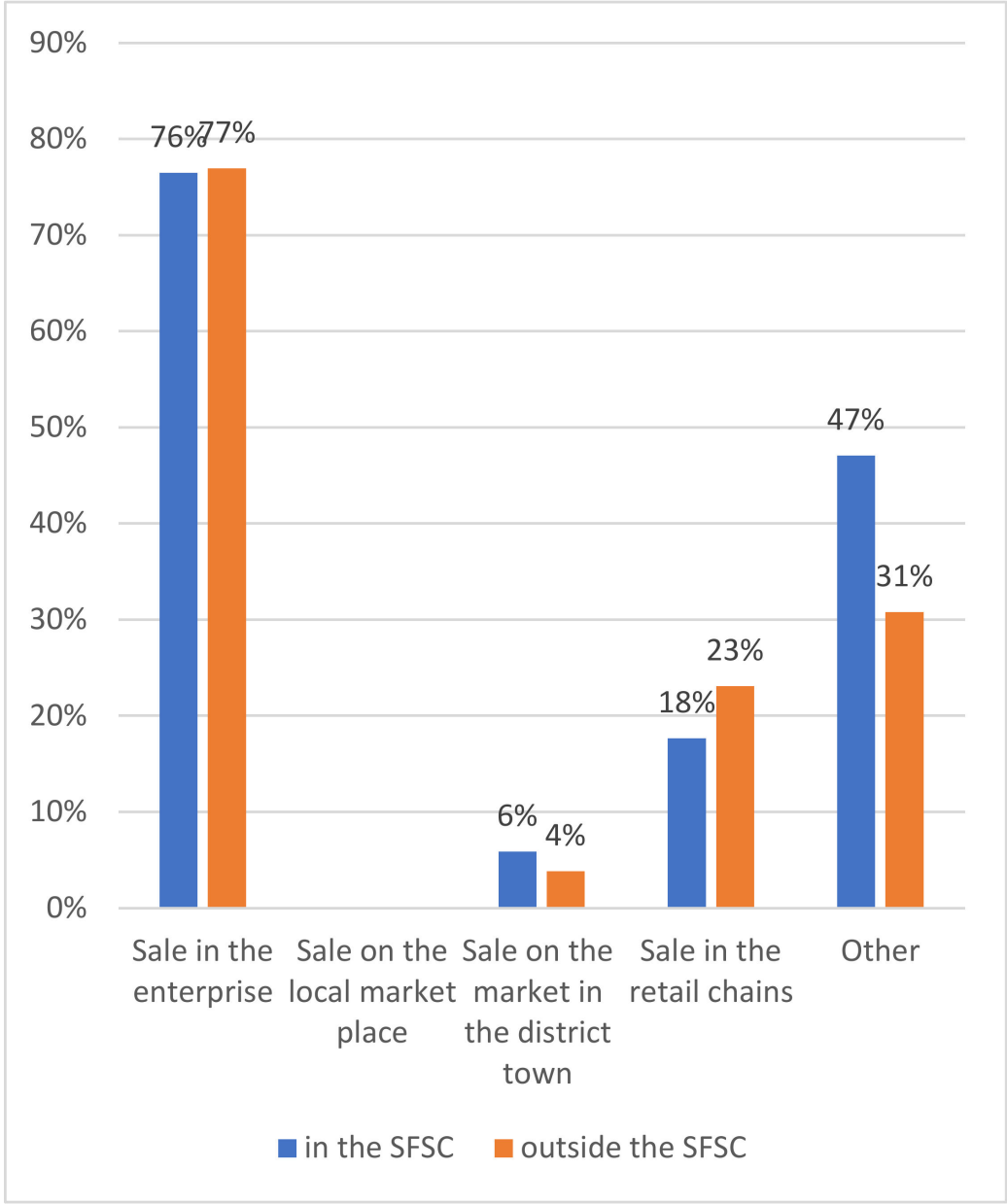

Figure 9. Comparison of enterprises in and outside the SFSC by way of selling products outside the enterprise. Source: Own processing.

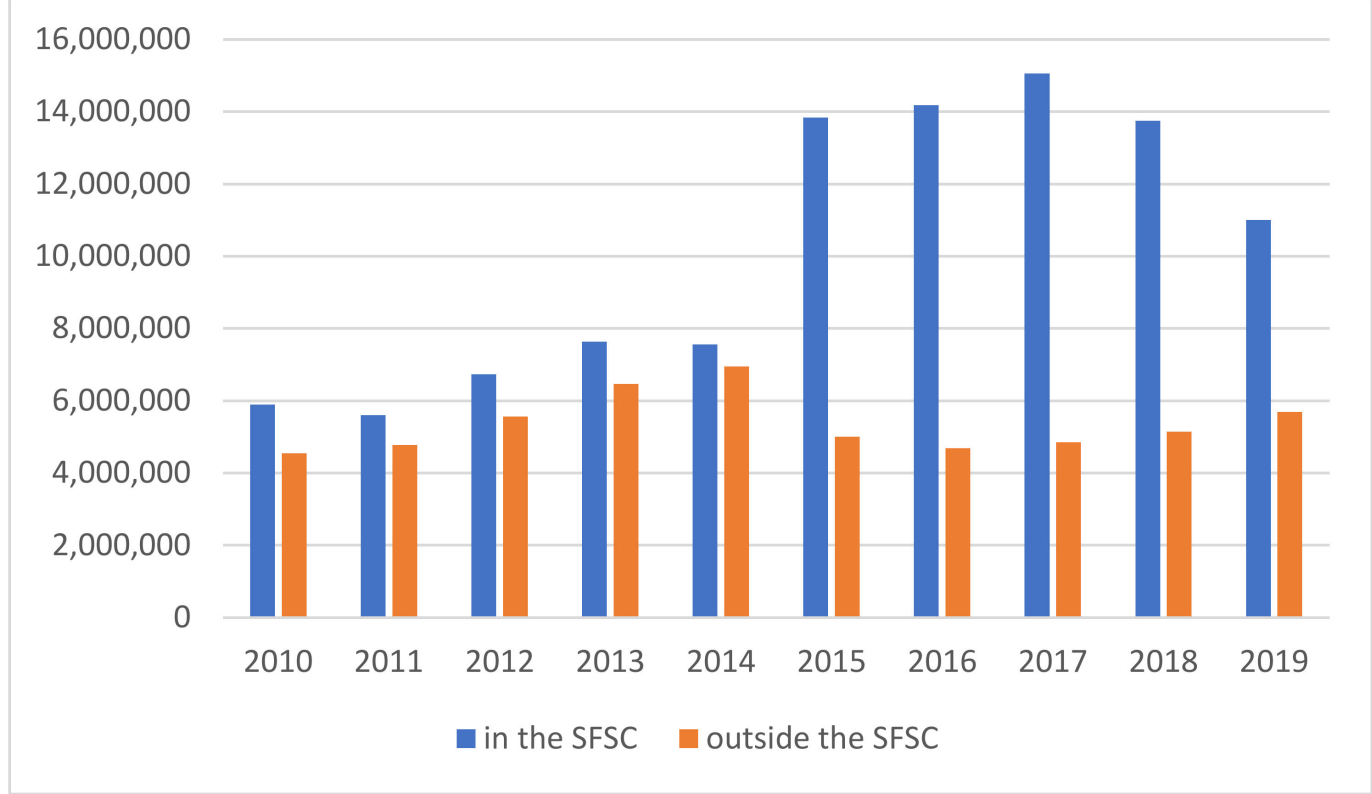

Figure 10. Comparison of enterprises inside and outside the SFSC according to the arithmetic mean of the operating expenses (EUR). Source: Own processing. 
The highest costs of economic activity were achieved by enterprises in the SFSC in 2017, but in 2018 and 2019, when we assume that most companies were already operating in the SFSC, we observed a slight decrease in costs. This fact suggests that shortening the distance in the supply chain and its complete minimization through sales directly in the enterprise, could lead to a reduction in transport costs, which could be reflected in the (reduced) cost of economic activity). We observed the opposite trend in enterprises outside the SFSC, where micro-enterprises make up $42 \%$ of the surveyed entities. Despite the fact that $77 \%$ of enterprises outside the SFSC sell their products directly in the enterprise, we observed a slight increase in the costs of economic activity from these enterprises from 2016 until the end of the observed period. Shortening distances in SFSC can bring benefits to enterprises, which in our case we perceive in terms of transport savings.

We also investigated whether there is a relationship between the examined primary and secondary data in terms of dependence. In the given time period (2010-2019), we monitored the independent variables of sales of own products, area, number of employees, amount of support, and membership (1) or non-membership (2) in the SFSC, with the aim being to evaluate the impact of each factor on operating income (dependent variable).

Using the forward stepwise regression analysis method, we added independent variables individually to the model at each step of the regression until we reached the best regression model, which has two statistically significant variables, as shown in the regression summary for the dependent variable (Table 1).

Table 1. Regression summary for the dependent variable income in the first regression model.

\begin{tabular}{|c|c|c|c|c|c|c|}
\hline \multirow{2}{*}{$\mathbf{N}=\mathbf{2 0}$} & \multicolumn{6}{|c|}{$\begin{array}{l}\text { Regression Summary for Dependent Variable: Income } R=0.79412668 ; R 2=0.63063718 \text {; Adjusted } \\
R 2=0.58718274 ; F(2,17)=14.513 ; p<0.00021 \text {; Std. Error of Estimate: } 2,417,801.03\end{array}$} \\
\hline & $\mathbf{b}^{*}$ & Std. Err. of $b^{*}$ & $\mathbf{b}$ & Std. Err. of b & $\mathbf{t}(17)$ & $p$-Value \\
\hline Intercept & & & $7,907,864$ & $1,219,486$ & 6.48459 & 0.000006 \\
\hline Member SFSC/POs & 2.22268 & 0.601792 & $16,304,612$ & $4,414,484$ & 3.69344 & 0.001803 \\
\hline Acreage & -1.57683 & 0.601792 & $-14,078$ & 5373 & -2.62023 & 0.017914 \\
\hline
\end{tabular}

Source: Own processing.

However, from the correlation/scatter plots of residuals and independent variables (Figures 11 and 12), we found a violation of the assumption of equality of residuals' variances.

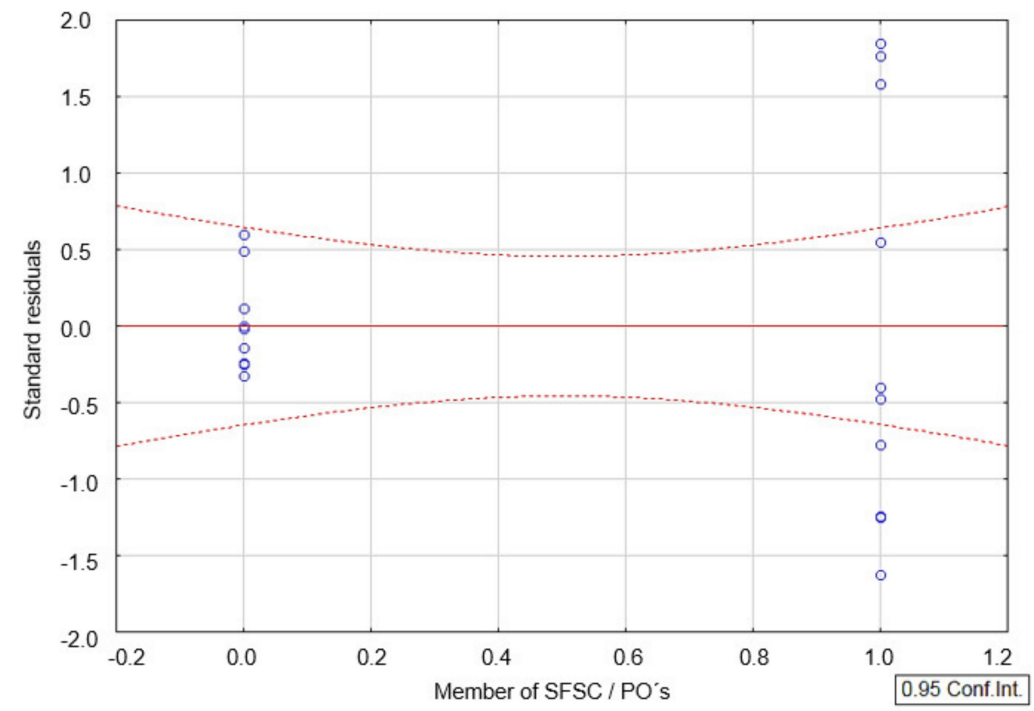

Figure 11. Violation of the equal residual variance assumption for the independent variable SFSC/POs. Source: Own processing. 


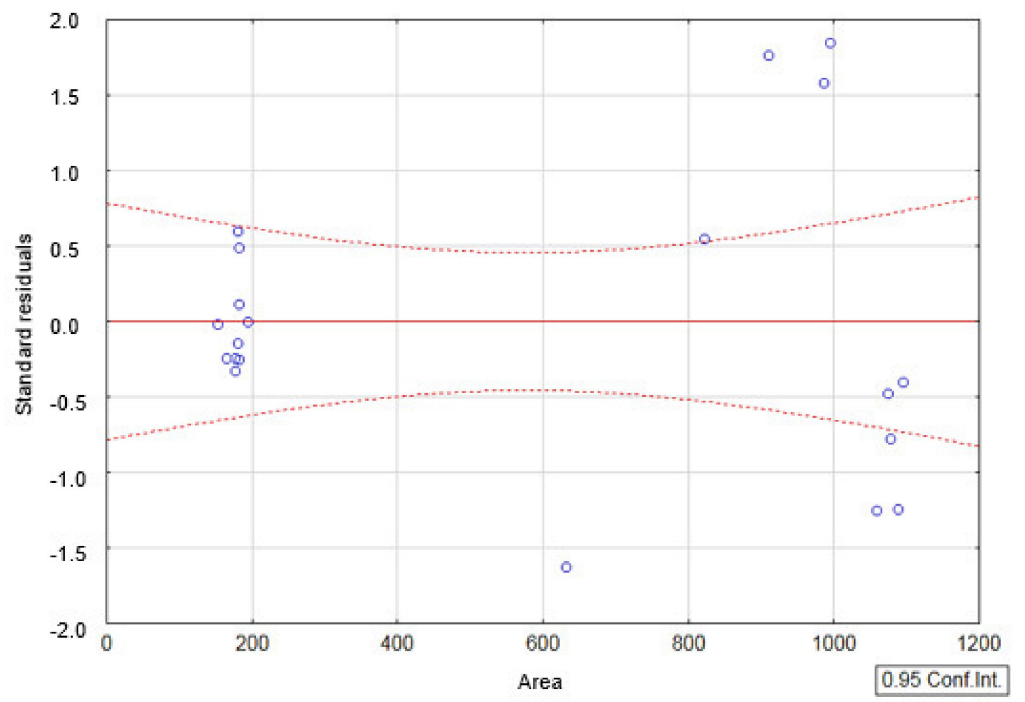

Figure 12. Violation of the equal residual variance assumption for the independent acreage variable. Source: Own processing.

From the figures, it is evident that the dispersion of residues changes with the increasing value of the independent variable (SFSC/POs member/acreage). In order for the model to be valid, it is necessary to eliminate the assumption violation through the transformation of the dependent variable; specifically, we use the natural logarithm to stabilize the variance, according to the relation $Y=\ln$ income

We proceed as in the creation of the first regression model, i.e., in the period 2010-2019 we monitor the independent variables of sales, area, employees, amount of support, and membership (1) or non-membership (2) in SFSC/POs, while evaluating the impact of each factor on the transformed dependent variable, i.e., the natural logarithm of the income (dependent variable). Using the forward stepwise regression analysis method, we added independent variables individually to the model at each step of the regression (Table 2) until we achieved the best regression model.

Table 2. Stepwise regression summary for the second regression model for the dependent variable $\ln$ (income).

\begin{tabular}{llllllll}
\hline \multirow{2}{*}{ Variable } & \multicolumn{2}{l}{ Summary of Stepwise Regression; DV: ln(Income) } & & \\
\cline { 2 - 8 } & $\begin{array}{l}\text { Step } \\
+ \text { In/-Out }\end{array}$ & $\begin{array}{l}\text { Multiple } \\
\text { R }\end{array}$ & $\begin{array}{l}\text { Multiple } \\
\text { R-Square }\end{array}$ & $\begin{array}{l}\text { R-Square } \\
\text { Change }\end{array}$ & $\begin{array}{l}\text { F-To } \\
\text { Entr/Rem }\end{array}$ & $\boldsymbol{p}$-Value & $\begin{array}{l}\text { Variables } \\
\text { Included }\end{array}$ \\
\hline Member SFSC/POs & 1 & 0.744904 & 0.554881 & 0.554881 & 22.43865 & 0.000165 & 1 \\
Acreage & 2 & 0.829946 & 0.688810 & 0.133929 & 7.31640 & 0.015021 & 2 \\
Sales & 3 & 0.843323 & 0.711194 & 0.022384 & 1.24009 & 0.281903 & 3 \\
Amount of support & 4 & 0.869803 & 0.756557 & 0.045363 & 2.79509 & 0.115278 & 4 \\
Employees & 5 & 0.871447 & 0.759420 & 0.002862 & 0.16657 & 0.689348 & 5 \\
\hline
\end{tabular}

Source: Own processing.

Table 3 tabulates the regression summary with the estimate of the model parameters. The model, where we calculate the statistically significant variables of membership and acreage, represents $68.88 \%$ of the variability of the natural logarithm of income:

$$
\text { ln income }=15.75883+1.78572 \text { member SFSC/POs }-0.00148 \text { acreage } .
$$

Using this model, we can make predictions of the development of income depending on the membership in the SFSC and the change in acreage. The natural logarithm of the dependent variable $Y$ will vary in accordance with the membership or non-membership 
of the enterprise in the SFSC/POs, as is indicated in the model. However, it will decrease with the increasing number of hectares (independent variable "acreage"). This result of the regression model is given by the fact that in Slovakia, the major acreage of agricultural land is farmed by the large agricultural enterprises, mainly represented by agricultural cooperatives or Ltd., usually farming the acreage of a couple of hundreds or, in some cases, thousands of hectares. These large agricultural enterprises usually focus their activities on the primary production (usually the general crop production). On the contrary, the micro and small agricultural enterprises with smaller acreage of agricultural land are usually specialised (since in terms of the general crop production, only farms larger that approximately 100 hectares of agricultural land are economically efficient). Since the smaller agricultural enterprises farm an acreage smaller than 100 hectares, they specialise their production on value-added products, and thus, their operating expenses are higher.

Table 3. Regression summary for the dependent variable ln(income)—second regression model.

\begin{tabular}{|c|c|c|c|c|c|c|}
\hline \multirow{2}{*}{$\mathbf{N}=\mathbf{2 0}$} & \multicolumn{6}{|c|}{$\begin{array}{l}\text { Regression Summary for Dependent Variable: } \ln (\text { Income }) \mathrm{R}=0.82994584 ; \mathrm{R} 2=0.68881009 ; \text { Adjusted } \\
\mathrm{R} 2=0.65219952 ; \mathrm{F}(2,17)=18.815 ; p<0.00005 ; \text { Std. Error of Estimate: } 0.24629\end{array}$} \\
\hline & $\mathbf{b}^{*}$ & $\begin{array}{l}\text { Std. Err. } \\
\text { of } b^{*}\end{array}$ & $\mathbf{b}$ & $\begin{array}{l}\text { Std. Err. } \\
\text { of } b\end{array}$ & $\mathbf{t}(17)$ & $p$-Value \\
\hline Intercept & & & 15.75883 & 0.124224 & 126.8583 & 0.000000 \\
\hline Member SFSC/POs & 2.19350 & 0.552373 & 1.78572 & 0.449685 & 3.9710 & 0.000987 \\
\hline Acreage & -1.49411 & 0.552373 & -0.00148 & 0.000547 & -2.7049 & 0.015021 \\
\hline
\end{tabular}

Source: Own processing.

In terms of the assumptions of using linear regression analysis, we verified the linear relationship between the dependent variable $Y$ and the independent variables $X$ using the correlation. Since the independent variable $X$ (member of SFSC/POs) is a dichotomous variable, we used a nonparametric correlation-Spearman's rank correlation coefficient (Table 4) - to verify the linear dependence between the dependent variable $Y$ (income) and independent variable $X$ (member of SFSC/POs). The value of Spearman $\mathrm{R}=0.797741$ is close to 1 , which indicates a direct relationship between the two variables. The $p$-value is $<0.05$, so the relationship is statistically significant.

Table 4. Verification of the dependence between the dependent and independent variables using the Spearman rank correlation coefficient.

\begin{tabular}{lllll}
\hline & \multicolumn{2}{l}{ Spearman Rank Order Correlations } & & $\boldsymbol{p}$-Value \\
\cline { 2 - 4 } Pair of Variables & $\begin{array}{l}\text { Valid } \\
\mathbf{N}\end{array}$ & $\begin{array}{l}\text { Spearman } \\
\mathbf{R}\end{array}$ & $\mathbf{t}(\mathbf{N}-2)$ & 0.000025 \\
\hline $\begin{array}{l}\text { Member SFSC/POs and } \\
\ln \text { (income) }\end{array}$ & 20 & 0.797741 & 5.612818 & \\
\hline
\end{tabular}

Source: Own processing.

Even in the case of verifying the linear relationship between the dependent variable $Y$ (income) and the independent variable $X$ (acreage) using the Pearson correlation coefficient, the positive correlation coefficient indicates a linear relationship between the examined variables, while the determination coefficient indicates that changing the acreage value will influence the value change of $\ln$ income to $40 \%$. This relationship is also statistically significant (Table 5). 
Table 5. Verification of the dependence between the dependent and independent variables using the Pearson correlation coefficient.

\begin{tabular}{lllll}
\hline \multirow{2}{*}{ Var. $\mathbf{X}$ and Var. $\mathbf{Y}$} & \multicolumn{2}{l}{ Parametric Correlations } & & $\mathbf{t}$ \\
\cline { 2 - 5 } & $\mathbf{R}(\mathbf{X}, \mathbf{Y})$ & $\mathbf{R 2}$ & $\mathbf{t}$-Value \\
\hline Acreage and $\ln ($ income) & 0.632575 & 0.400151 & 3.465191 & 0.002762 \\
\hline & Source: Own processing. & &
\end{tabular}

Using graphs of residues and independent variables, we verified the equality of the variance of residuals (Figures 13 and 14) while observing that the variance of residuals is significantly more stable compared to that of the first model, i.e., the assumption is no longer violated and the second model is more valid.

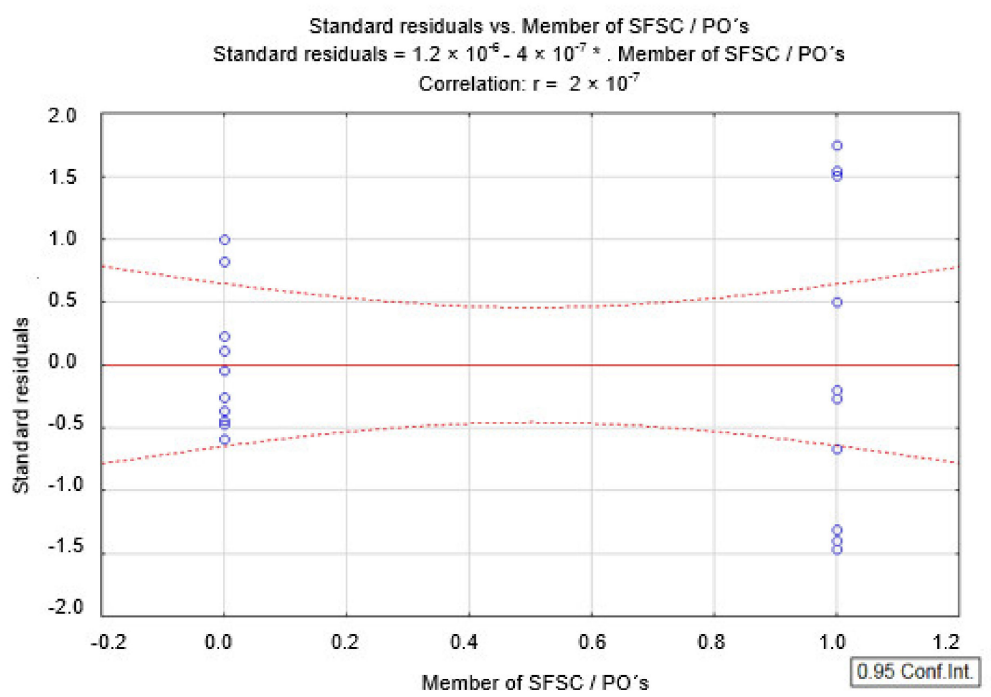

Figure 13. Equality of variance of residuals for the independent variable SFSC/POs. Source: Own processing.

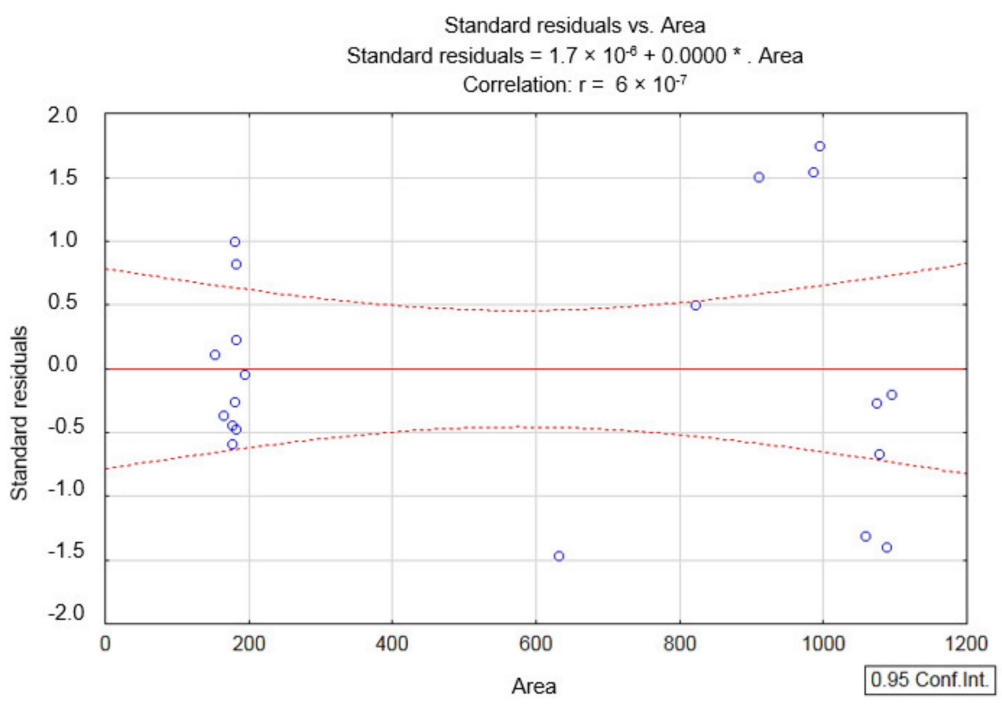

Figure 14. Equality of variance of residuals for the independent acreage variable. Source: Own processing. 
In the case of a normal distribution of residuals (Figure 15), we examined whether the points are as close as possible to the line, which is fulfilled in the case of model 2, corresponding to the normal distribution of residuals.

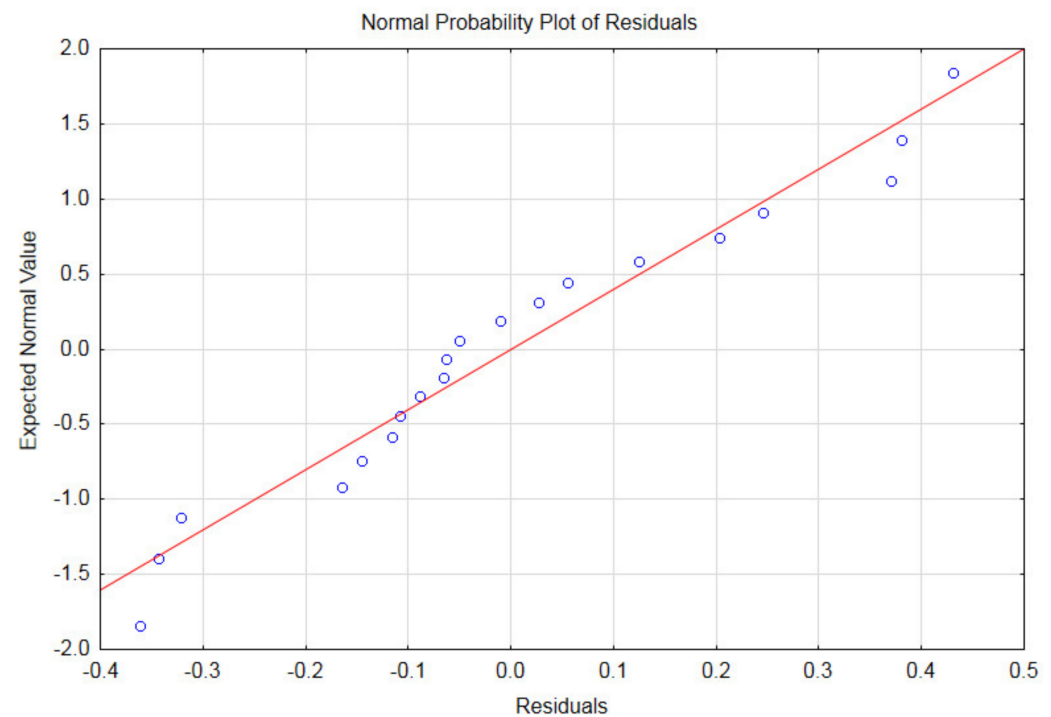

Figure 15. Normal distribution of residuals. Source: Own processing.

The independence of residues is verified by the so-called Durbin-Watson statistics, where we monitored its value of $\mathrm{d}$, as well as the value of serial correlation. In Table 6, it can be seen that the value of $d$ is very close to 2 and the value of the serial correlation is almost equal to 0 , which indicates the independence of the residuals.

Table 6. Independence of residuals verification using Durbin-Watson statistics.

\begin{tabular}{lll}
\hline & \multicolumn{2}{l}{ Durbin-Watson d and Serial Correlation of Residuals } \\
\cline { 2 - 3 } & Durbin-Watson d & Serial Corr. \\
\hline Estimate & 1.902681 & -0.001891 \\
\hline Source: Own processing. & &
\end{tabular}

Based on the above-mentioned findings, we can state that associating with the SFSC is important mainly for micro and small agricultural enterprises, even though the mediumsized enterprises can benefit from operating in the SFSC as well. The acreage of the farmed land and the size of the enterprise play an important role in its profit/loss from operations; since agricultural enterprises larger that approximately 100 hectares of agricultural land are economically efficient, smaller enterprises need to specialise their production and make value-added products to be competitive towards larger enterprises. Such specialisation presupposes the implementation of agricultural procedures beneficial for the climate and environment (also requested by the national authorities), including crop diversification and the preservation of permanent grasslands, terrasses, landscape elements, buffer zones, etc., which translates into higher operating expenses. Associating micro and small agricultural enterprises (often with the medium-sized enterprises) with the SFSC provides them with an opportunity to compensate for these expenses using the SFSC benefits, such as improved product sales, better marketing, or production of the value-added products through joint activities, such as the joint marketing of products, sharing of production premises, or joint logistics and transport. Using the SFSC benefits and the implementation of joint activities is then reflected in improved operating income. The forward stepwise regression analysis method confirmed a linear relation between the operating income (dependent variable) and the membership/non-membership in the SFSC (dichotomous independent variable). 
The developed regression model, however, pointed out that the acreage is an important factor, especially for micro and small agricultural enterprises, which need to specialise their production, and this specialisation is with increasing acreage reflected in higher operating expenses.

\section{Discussion}

In Section 3, we stated the achievement of the defined objectives, based on the goals set in the program documents, specifically in the RDP SR 2014-2020. Part of the discussion is based on the comparison of our findings to authors dealing with related topics. When assessing the added value of products as an important factor, in the available literature, the term "local" is connected with the term "quality", which is supported by the statement of, e.g., Goodman and Goodman (2009), according to which alternative food networks are defined in this case, among other things, by promoting local, quality specialty foods [11]. This is, however, in contradiction to the statement that SFSCs do not necessarily lead to increased added value on farms [25]. However, quality local products are directly related to the objectives set in the RDP SR 2014-2020, while the higher added value of products in relation to their quality also contributes to the fulfilment of the RDP objectives [27].

As for improving the social situation of farmers through increased incomes, we found that all enterprises within the SFSC stated that their activities in the SFSC improved the social situation of their families through increased incomes, which is in compliance with the description of the Need No. P4 Support sales of domestic production through sales organizations of producers and the development of short supply chains within the RDP SR 2014-2020 [27]. This finding is supported by the statements of some authors, e.g., profit is needed to operate on a long-term basis [23], and SFSCs are perceived as beneficial mainly from the economic perspective [24]; however, other authors (Mundler and Laughrea, 2016) do not attach much importance to the economic weight of the SFSC [25]. On the other hand, other factors need to be considered, especially the main activities of researched enterprises, which we think play a role in their specialisation and thus affect their operating expenses. Mainly micro and small enterprises need to specialise their production and produce value-added products. Looking at Figure 3, it can be seen that most of the researched enterprises focus on growing of pome fruits and stone fruits, including the cultivation of selected species of fruits with high and very high labour input. This also applies to the growing of vegetables and melons and roots and tubers. This specialisation requires the implementation of agricultural procedures beneficial for the climate and environment, which is requested by the national authorities as well. These procedures include crop diversification and the preservation of permanent grasslands, terrasses, landscape elements, buffer zones, etc. Following these requirements, however, translates into increased operating expenses. Associating micro and small agricultural enterprises (often with the medium-sized enterprises) with the SFSC provides them with an opportunity to compensate for these expenses using the SFSC benefits, as described in the Results section. Based on these findings and based on the primary and secondary data collected and processed from the questionnaire and available public resources, we can state that on the national level (i.e., within the territory of Slovakia), the farmers operating in the SFSC meet the relevant objectives given in the RDP SR 2014-2020, especially concerning achieving a higher added value of their products and improving their social situation through increased incomes. However, this statement is to some extent ambiguous when we compare it with the findings of international authors.

As for the advantages (or benefits) and disadvantages of operating in the SFSC, we start from the statements of some authors (e.g., Galli and Brunori, 2013) that the main disadvantages of micro and small agricultural enterprises compared to large ones are the high production costs and the prices at which they sell their products [17]. A possible solution is the maximum possible distance reduction in the supply chain in order to minimize transport costs, as well as implementation of measures to improve product sales. While the savings by reducing traffic are mentioned by some authors as a possible 
solution [6], in terms of improving the sales, Kneafsey et al. (2013) state that shortening the number of links in the supply chain results in increased local sales, in-creased demand for local services, and increased labour markets [8]. By analysing the secondary data, we found a decrease in the operating expenses of enterprises operating in the SFSC in the last two monitored years. In connection with this, we argued that shortening the distance in the supply chain and its complete minimization through direct (on-farm) sales could have led to a reduction in transport costs (see Rong et al., 2011), which could have affected (i.e., reduced) the operating expenses. This finding is in compliance with some authors [21], who stated that the SFSC concept is connected with direct sales, higher quality healthy local products, promoting the territory with the marketing of local food products, and reducing the distances between consumer and local producers. Other authors (e.g., Canfora, 2015) expect positive results of operating in the SFSC from the economic and environmental point of view [20]. We took these statements into consideration and adjusted the questionnaire distributed to agricultural enterprises accordingly, forming the questions to focus on the economic, social, and environmental benefits of operating in the SFSC. We found that the majority of responding enterprises prefers the direct (on-farm) sale and finds the joint marketing and improved sales of their products to be the main advantages (benefits) of operating in the SFSC. These findings, however, do not indicate that enterprises outside the SFSC do not sell their products directly, or that they do not produce high-quality value-added products.

\section{Conclusions}

The main objective of the submitted paper was to demonstrate the assessment of the implementation of a short food supply chain in the conditions of the Slovak Republic. In relation to this we have focused in particular on the assessment of farmers' performance in short food supply chains in terms of meeting the objectives set out in the Rural Development Program of the Slovak Republic 2014-2020, with special attention to a higher added value of the products offered and improving the social situation through increased incomes. Within the overall assessment process, we have also demonstrated the advantages and disadvantages of grouping farmers into short food supply chains, especially in terms of selected economic factors. Based on the findings and relevant references, it is possible to demonstrate that from the point of view of SFSC characteristics the term "local" is combined with the term "quality". Quality local products are directly related to the objectives set in the RDP SR 2014-2020, while the higher added value of products in relation to their quality also contributes to the fulfilment of the RDP objectives. From the improvement of the social situation of farmers point of view, we found that all enterprises within the SFSC stated that their activities in the SFSC improved the social situation of their families through increased income. In addition to the analysis of primary and secondary data, we can state that the main disadvantages of micro and small enterprises compared to large companies are the high production costs and prices at which they sell their products. A possible solution is the maximum possible distance reduction in the supply chain in order to minimize transport costs, as well as measures to increase product sales, while the "economic gains provided by less transportation" are also supported by relevant references stated in the paper. In terms of increased sales, it is expected that "shortening the number of links in the supply chain results in increased local sales, increased demand for local services, and increased labour markets". By analysing the secondary data, we identified a decrease in the operating expenses of enterprises operating in the SFSC in the last two monitored years. In connection to this, we argued that shortening the distance in the supply chain and complete minimization through in-house sales could have led to a reduction in transport costs, which could have affected the operating expenses (their reduction). Summing up the findings and results mentioned above leads us to the interpretation that grouping farmers into short food supply chains is advantageous, especially in terms of selected economic factors, thus achieving of the second partial objective of the paper. 


\begin{abstract}
Author Contributions: All authors contributed to preparation of the paper. The part focused on methodology and data analysis was prepared by N.F., P.S., and L.S.; statistical analysis of the data was prepared by M.M.; the preparation of the first draft of the paper was done by N.F.; all authors contributed to the paper's present form, with a final collective revision. All authors have read and agreed to the published version of the manuscript.
\end{abstract}

Funding: This research was funded by European Education and Culture Executive Agency grant number 611446-EPP-1-2019-1-SK-EPPJMO-CoE.

Institutional Review Board Statement: Not applicable.

Informed Consent Statement: Not applicable.

Data Availability Statement: The data used to support the findings of this study are available from the corresponding author upon request.

Acknowledgments: This paper was prepared with the support of the Erasmus+ Jean Monnet project "Centre of Excellence for European Agri-Food Chain-CEEAG" No. 611446-EPP-1-20191-SK-EPPJMO-CoE. The European Commission support for the production of this publication does not constitute an endorsement of the contents, which reflect the views only of the authors, and the Commission cannot be held responsible for any use which may be made of the information contained therein.

Conflicts of Interest: The authors declare no conflict of interest.

$\begin{array}{ll}\text { Abbreviations } \\ \text { AFN } & \text { Alternative food networks } \\ \text { CAP } & \text { Common agricultural policy } \\ \text { CSA } & \text { Community supported agriculture } \\ \text { EU } & \text { European Union } \\ \text { LFS } & \text { Local food systems } \\ \text { NACE } & \text { Statistical Classification of Economic Activities in the European Community } \\ \text { POs } & \text { Producer Organizations } \\ \text { SFSC } & \text { Short food supply chains } \\ \text { SMEs } & \text { Small and medium-sized enterprises } \\ \text { RDP } & \text { Rural Development Programme }\end{array}$

\title{
References
}

1. Schneider, U.; Havlík, P.; Schmid, E.; Valin, H.; Mosnier, A.; Obersteiner, M.; Böttcher, H.; Skalský, R.; Balkovič, J.; Sauer, T.; et al. Impacts of population growth, economic development, and technical change on global food production and consumption. Agric. Syst. 2011, 104, 204-215. [CrossRef]

2. Nunn, N.; Qian, N. The potato's contribution to population and urbanization: Evidence from a historical experiment. Q. J. Econ. 2011, 126, 593-650. [CrossRef] [PubMed]

3. Marsden, T.; Smith, E. Ecological entrepreneurship: Sustainable development in local communities through quality food production and local branding. Geoforum 2005, 36, 440-451. [CrossRef]

4. Ilbery, B.; Maye, D.; Kneafsey, M.; Jenkins, T.; Walkley, C. Forecasting food supply chain developments in lagging rural re-gions: Evidence from the UK. J. Rural Stud. 2004, 20, 331-344. [CrossRef]

5. De Fazio, M. Agriculture and sustainability of the welfare: The role of the short supply chain. Agric. Agric. Sci. Procedia 2016, 8 , 461-466. [CrossRef]

6. Rong, A.; Akkerman, R.; Grunow, M. An optimization approach for managing fresh food quality throughout the supply chain. Int. J. Prod. Econ. 2011, 131, 421-429. [CrossRef]

7. Gralton, A.; Vanclay, F. Artisanality and culture in innovative regional agri-food development: Lessons from the Tasmanian artisanal food industry. Int. J. Foresight Innov. Policy 2009, 5, 193-204. [CrossRef]

8. Kneafsey, M.; Venn, L.; Schmutz, U.; Balázs, B.; Trenchard, L.; Eyden-Wood, T.; Bos, E.; Sutton, G.; Blackett, M. Short Food Supply Chains and Local Food Systems in the EU. A State of Play of their Socio-Economic Characteristics. JRC Sci. Policy Rep. 2013, 123, 129.

9. Brunori, G.; Galli, F.; Barjolle, D.; Van Broekhuizen, R.; Colombo, L.; Giampietro, M.; Kirwan, J.; Lang, T.; Mathijs, E.; Maye, D.; et al. Are Local Food Chains More Sustainable than Global Food Chains? Considerations for Assessment. Sustainability 2016, 8 , 449. [CrossRef] 
10. Renting, H.; Marsden, T.K.; Banks, J. Understanding alternative food networks: Exploring the role of short food supply chains in rural development. Environ. Plan. A 2003, 35, 393-411. [CrossRef]

11. Goodman, D.; Goodman, M. Alternative Food Networks. In International Encyclopedia of Human Geography; Elsevier: Amsterdam, The Netherlands, 2009; pp. 208-220.

12. Maye, D.; Kirwan, J.; Alternative Food Networks. Sociopediaisa. Available online: https://sociopedia.isaportal.org/resources/ resource/alternative-food-networks / (accessed on 1 December 2021).

13. Aubry, C.; Kebir, L. Shortening food supply chains: A means for maintaining agriculture close to urban areas?, The Case of the French Metropolitan Area of Paris. Food Policy 2013, 41, 85-93. [CrossRef]

14. Falguieres, M.; Kumar, V.; Garza-Reyes, J.A.; Kumari, A.; Lim, M.K.; Rocha-Lona, L. Investigating the impact of short food supply chain on emigration: A study of Valencia community in Spain. IFAC-PapersOnLine 2015, 48, 2226-2232. [CrossRef]

15. Ministry of Agriculture of the Slovak Republic. Green Report 2009. Available online: https://www.mpsr.sk/en/index.php? navID=17\&id=26 (accessed on 2 December 2021).

16. Rural Development Programme of the Slovak Republic 2007-2013. Available online: https://www.mpsr.sk/en/index.php? navID=7\&id=30 (accessed on 2 December 2021).

17. Galli, F.; Brunori, G. Short Food Supply Chains as Drivers of Sustainable Development; Evidence Document; Laboratorio di Studi Rurali Sismondi: Pisa PI, Italy, 2013.

18. Van der Ploeg, J.D.; Renting, H.; Brunori, G.; Knickei, K.; Mannion, J.; Marsden, T.; De Roest, K.; Sevilla-Guzmán, E.; Ventura, F. Rural development: From practices and policies towards theory. Sociol. Rural. 2000, 40, 391-408. [CrossRef]

19. Marsden, T.; Banks, J.; Bristow, G. Food supply chain approaches: Exploring their role in rural development. Sociol. Rural. 2000, 40, 424-438. [CrossRef]

20. Canfora, I. Is the Short Food Supply Chain an Efficient Solution for Sustainability in Food Market? Agric. Agric. Sci. Procedia 2016, 8, 402-407. [CrossRef]

21. Bisogno, M. Corporate Social Responsibility and Supply Chains: Contribution to the Sustainability of Well-being. Agric. Agric. Sci. Procedia 2016, 8, 441-448. [CrossRef]

22. Jarzębowski, S.; Bourlakis, M.; Bezat-Jarzębowska, A. Short Food Supply Chains (SFSC) as Local and Sustainable Systems. Sustainability 2020, 12, 4715. [CrossRef]

23. Demartini, E.; Gaviglio, A.; Pirani, A. Farmers' motivation and perceived effects of participating in short food supply chains: Evidence from a North Italian survey. Agric. Econ. (Agricecon) 2017, 63, 204-216. [CrossRef]

24. Malak-Rawlikowska, A.; Majewski, E.; Wąs, A.; Borgen, S.O.; Csillag, P.; Donati, M.; Freeman, R.; Hoàng, V.; Lecoeur, J.L.; Mancini, M.C.; et al. Measuring the Economic, Environmental, and Social Sustainability of Short Food Supply Chains. Sustainability 2019, 11, 4004. [CrossRef]

25. Mundler, P.; Laughrea, S. The contributions of short food supply chains to territorial development: A study of three Quebec territories. J. Rural Stud. 2016, 45, 218-229. [CrossRef]

26. Zirham, M.; Palomba, R. Female Agriculture in the Short Food Supply Chain: A New Path towards the Sustainability Empowerment. Agric. Agric. Sci. Procedia 2016, 8, 372-377. [CrossRef]

27. Rural Development Programme of the Slovak Republic 2014-2020. Available online: https:/ /www.mpsr.sk/ program-rozvojavidieka-sr-na-programove-obdobie-2014-2020/1180-43-1180-8644/ (accessed on 3 December 2021.).

28. Eurostat. Available online: http:/ / appsso.eurostat.ec.europa.eu/nui/show.do?dataset=ef_m_farmleg\&lang=en (accessed on 1 December 2021).

29. Eurostat. Agriculture Statistics-Family Farming in the EU. Available online: https:/ / ec.europa.eu/eurostat/statistics-explained/ index.php?title=Agriculture_statistics_-_family_farming_in_the_EU (accessed on 1 December 2021).

30. Summary Overview of the Project Measures RDP SR 2014-2020 to 31.12.2017. Agricultural Paying Agency. Available online: http:/ / www.apa.sk/download/12406 (accessed on 6 December 2021).

31. Summary Overview of the Project Measures RDP SR 2014-2020 to 31.12.2020. Agricultural Paying Agency. Available online: http:/ / www.apa.sk/download/16809 (accessed on 6 December 2021).

32. Ministry of Finance of the Slovak Republic. Register of Financial Statements. 2011. Available online: https://www.registeruz.sk/ cruz-public/domain/accountingentity/simplesearch (accessed on 30 November 2021).

33. Munk, M. Počítačová Analýza Dát; Univerzita Konštantína Filozofa: Nitra, Slovakia, 2011; pp. 221-225. ISBN 978-80-8094-895-5. 